\title{
PECULIARIDADES DO PROCESSO CIVIL AMBIENTAL
}

Marcelo Farina de Medeiros, Lilian Carla dos Santos

Universidade Estadual Paulista - UNOESTE. Curso de Direito, Presidente Prudente, SP. e-mail: mfmedeiros@unoeste.br

\section{RESUMO}

Com a constitucionalização do Direito Ambiental, em 1988, tornou-se possível a edição de normas que tivessem como objetivo a proteção do meio ambiente e garantindo assim qualidade de vida ao ser humano. No entanto, para se tornar efetiva a proteção ao bem ambiental, ao lado de normas materiais protetivas surge a necessidade de normas processuais aptas a atender às particularidades desse ramo do direito. Por se tratar de matéria que atinge direitos transindividuais, ou seja, abrange interesse de grupos e indivíduos indetermináveis, a utilização do microssistema processo coletivo, aliando regras do sistema previsto no Código de Processo Civil às particularidades das leis 7.347/85 e 8.072/90, é medida satisfatória para preservação deste macrobem. Assim, como o sistema do Código de Processo Civil não alcança de forma satisfatória a proteção dos direitos difusos, necessários se faz o diálogo das fontes entre sistema e microssistema.

Palavras - chave: Direito Difuso, Processo Coletivo, Peculiaridades.

\section{ENVIRONMENTAL CIVIL PROCEDURE PECULIARITIES}

\begin{abstract}
With the rise of environmental law at the level of constitutional law, which in Brazil happened in 1988, it became possible to issue regulations that have the objective of protecting the environment and ensuring quality of human life. However, to become effective the protection of environmental right, as well as the material standards arises the need for procedural rules that met all the peculiarities of this rigth. Because of that affects trans rights, covers interest indeterminable persons, the use of microsystem collective process, combining system rules of the Civil Procedure Code with peculiarities of the laws 7.347/85 and $8.072 / 90$ is satisfactory for preserving the environmental rights. As the system of the Civil Procedure Code does not reach a satisfactory manner the protection of diffuse rights, becomes necessary dialogue between the source system and microsystem.
\end{abstract}

Keywords: Diffuse Rigth, Collective Procedure, Peculiarities. 


\section{INTRODUÇÃO}

O Direito, como normatização social, não pode ficar alheio às evoluções da sociedade. A permissibilidade, a obrigatoriedade e a proibilidade são as três modalidades de normatizar fatos. A problematização surge, no entanto, quando a forma tradicional de solução de conflitos não prevê, em abstrato, consequências jurídicas para determinados atos, ou não tem procedimento preparado para atender ao direito material.

A partir da Revolução Industrial indivíduos se viram unidos por um interesse comum: a resistência aos abusos laborais. Desta união teve início a concepção de interesse transindividual, que extrapola o interesse de um indivíduo isoladamente. A reunião de pessoas mediante interesses comuns representou uma significativa mudança social que teria de ser regulamentada pelo Direito. Outro importante fato que alterou as bases sociais foi a reconstrução de diversos países, no período pós-segunda guerra mundial, que revolucionou o comércio multilateral entre Estados, iniciado nas grandes navegações dos séculos XV e XVI, e aprofundou a produção em massa iniciada na revolução industrial, dando início à globalização. Esta gerou profundas transformações nas relações de produção e consumo, dando ensejo à necessidade de proteção do consumidor hipossuficiente.

Além das quebras de paradigmas acima citadas, foi revelada também a existência de outros grupos vulneráveis, como idosos e crianças, além de direitos que extrapolam grupos sociais ou classes de pessoas, porque atingem uma parcela indeterminável de indivíduos, os direitos difusos, como é o caso do meio ambiente ecologicamente equilibrado. Assim, o ordenamento jurídico teve de se adequar para a nova classe de direitos transindividuais, os difusos. 0 direito individual, de base liberal, não foi suficiente para atender às demandas difusas, o que resultou na reformulação das estruturas normativas. Esta reformulação se convencionou denominar por pósmodernismo ou neoconstitucionalismo, caracterizando-se pela construção de um ordenamento jurídico pautado em Princípios e normas, hábil a atender a todas as necessidades da organização social e se adequar às novas demandas. A constitucionalização do direito ambiental e sua concepção como direito fundamental eleva a necessidade de instrumentos de efetividade à sua tutela. Não bastam, contudo, normas de direito material aptas a regulamentar as novas demandas sociais, mas, o direito material necessariamente deve ser acompanhado da evolução processual, 
como instrumento de sua efetivação. Objetiva, portanto, o presente trabalho, por meio do método dedutivo e sistêmico, apontar as peculiaridades do microssistema processual coletivo, como forma de efetivação dos direitos transindividuais, com especial atenção ao direito ambiental.

\section{CONSTITUCIONALIZAÇÃO E TUTELA DO MACROBEM AMBIENTAL}

O direito ambiental tutela as relações do homem com a natureza, no intuito de assegurar a sadia qualidade da vida humana.

A Constituição Portuguesa de 1976 foi pioneira a relacionar o meio ambiente natural à vida humana, dispondo que "[...] todos têm direito a um ambiente de vida humano, sadio e ecologicamente equilibrado e o dever de o defender"1 ${ }^{1}$. Fruto do pósmodernismo, o Direito Ambiental brasileiro teve ascensão na sua constitucionalização, que só veio a ocorrer no Brasil em 1988. A Constituição Federal brasileira, seguindo o exemplo português, tem como fundamento da tutela do meio ambiente a qualidade de vida do ser humano.

O Direito Ambiental, fruto da categoria de direitos difusos, cuja controvérsia é sobre interesses de grupos indetermináveis e a conflitualidade do objeto frequentemente colide entre interesses de

${ }^{1}$ PORTUGAL. Constituição (VII Revisão Constitucional). Disponível em:

<http://www.parlamento.pt/Legislacao/Paginas/ConstituicaoRepubl icaPortuguesa.aspx>. Acesso em: 15 ago. 2014. grupos, classes ou categorias de pessoas, reclama uma nova ótica não só material como também processual. O Código de Processo Civil, baseado na legitimidade ordinária e na coisa julgada individual, é incapaz de responder satisfatoriamente aos direitos difusos, em que é impossível a quantificação individual de direitos. Portanto, ao lado da regulamentação das condutas por meio das normas de direito material foi necessária a criação de um microssistema processual capaz de conferir efetividade ao direito de ação, nas demandas transindividuais.

As peculiaridades da defesa judicial dos interesses difusos reclamam regras processuais próprias, tais como a representação ou substituição processual do grupo lesado; a extensão da coisa julgada para além das partes formais do processo; a repartição do produto de eventual indenização entre titulares indetermináveis; e a figura de um processo coletivo, destinado à composição e decisão dos conflitos intersubjetivos, mediante regras próprias capazes de responder às excepcionalidades apontadas.

Falar sobre a preservação de direitos de pessoas que ainda nem nasceram ambiente saudável para as gerações futuras, desenvolvimento sustentável, etc. - reflete uma tutela de direito para entes despersonalizados, jamais pensado sistema 
comum tal como concebido por LIEBMAM e CARNELUTTI, ao analisar, respectivamente, as condições da ação e o conflito de interesses com sua evolução para a lide.

As clássicas condições da ação, concebidas por LIEBMAM, em especial o interesse processual e a legitimidade das partes, reclamam, segundo Barbi (1998), uma lesão efetiva ou, no mínimo, uma ameaça atual e objetiva ao direito do autor, que deve necessariamente coincidir com o lesado protegido pela lei ${ }^{2}$. A ação deve seguir pela legitimidade ordinária em face de um dano atual ou iminente. A tutela ambiental, entretanto, dispensa a atualidade e certeza do dano, abrangendo tutela preventiva, direito de entes despersonalizados e até mesmo de pessoas que ainda nem existem gerações futuras (artigo 225 da Constituição Federal). $\mathrm{O}$ bem ambiental supera, outrossim, o conflito de interesses concebido por CARNELUTTI, que pressupõe a existência de um confronto entre partes determinadas e a existência prévia do direito de uma delas. Na tutela da defesa do meio ambiente é licito se ajuizar ação civil em nome de pessoas que sequer nasceram, para prevenir danos que tampouco ocorreram.

O equilíbrio ambiental é tratado como macrobem, pois inclui microbens bióticos e abióticos, "[...] portanto, embora o objeto de

2 BARBI, C.A. Comentários ao Código de Processo Civil. Rio de Janeiro: Forense, 1998. v.1. p.25/38. proteção do direito ambiental seja o equilíbrio ecológico (macrobem), ele também cuida, inexoravelmente, da função ecológica exercida pelos fatores ambientais bióticos e abióticos (microbens)" ${ }^{3}$.

A transversalidade da tutela ambiental não se restringe à ciência do Direito, envolvendo ciências agrárias, econômicas, geológicas, entre outras. Ainda que limitado o estudo à ciência jurídica, o Direito Ambiental não admite uma análise isolada. É bastante complexo, pois guarda relação com todos os ramos do Direito. A saciedade desse estudo não é objeto do presente trabalho, que se limita ao direito processual civil ambiental. Paulo Roberto Pereira de Souza bem elucida a classificação transversal do direito ambiental no gráfico por ele desenvolvido:

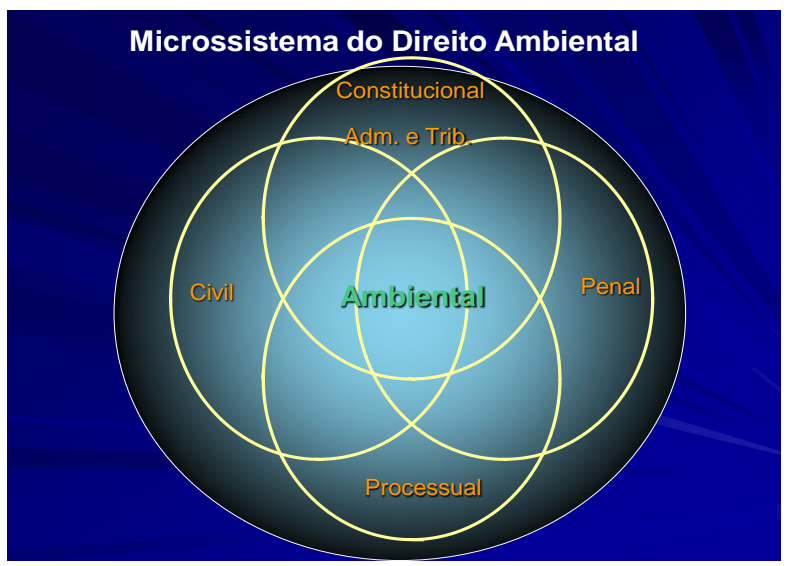

Figura 1. Esquema do microssistema do direito ambiental Fonte: Paulo Roberto Pereira de Souza ${ }^{4}$ Observa-se uma intersecção da tutela do Direito Ambiental em todos os ramos do

\footnotetext{
${ }^{3}$ RODRIGUES, M. A. Processo Civil Ambiental, 2. ed. São Paulo: Revista dos Tribunais, 2010. p.243.

${ }^{4}$ SOUZA, P.R.P. Meio Ambiente: memória e compromissos da Ordem dos Advogados do Brasil: 1989/2012, Brasília: OAB, Conselho Federal, Comissão Nacional de Direito Ambiental, 2012. p. 144.
} 
direito, concebidos na doutrina clássica, sob a legitimação constitucional. Assim, a interação da Constituição Federal com normas infraconstitucionais de direito coletivo, especialmente a lei da Ação Civil Pública (lei n. - 7.347/1985) e o Código de Defesa do Consumidor (lei 8.078/1990), com aplicação subsidiária do Código de Processo Civil (lei n.으 $5.869 / 1973)$, formam o microssistema processual do Direito Ambiental. Este visa a facilitar o acesso à justiça, gerar economia processual, contribuir para a redução de decisões judiciais conflitantes e alargar a tutela do macrobem ambiental.

Vale apontar que além dos institutos de processo coletivo em vigor, há em trâmite no Congresso Nacional um projeto de Código de Processo Coletivo (Projeto de Lei n.으 $5.139 / 2009)$ que, caso aprovado e promulgado disciplinará o processo das lides coletivas.

A função precípua do direito ambiental é prevenir agressões ao meio ambiente ecologicamente equilibrado. $\mathrm{O}$ artigo 225 da Constituição Federal fala expressamente em defender e preservar o meio ambiente e a lei n.o 6.938/1981, também dispõe neste sentido (art. 14, caput e $\S 1^{\circ}$ ). Enaltece-se, portanto, no processo coletivo, a importância das medidas processuais para obtenção de tutelas específica e cautelar. Rodrigues enfatiza que sempre que possível e no menor tempo possível, devem ser adotadas no processo ambiental técnicas de tutela específica e, só subsidiariamente, tutela reparatória in natura e, mais subsidiariamente ainda, a tutela indenizatória ${ }^{5}$. De início, portanto, conclui-se que todos os modos de tutela específica previstos no artigo 461, $\S 5$, do Código de Processo Civil, são perfeitamente aplicáveis no processo ambiental, assim como as ações de preceito cominatório.

O processo, como instrumento do direito material, só se legitima se for hábil ao fim a que ser propõe. Portanto, o processo coletivo deve ser dotado de peculiaridades especiais para atingir o grau de sua utilidade que produza uma tutela jurisdicional efetiva, tais como a titularidade disjuntiva, regras especiais sobre competência de foro, ônus da prova, sentença e relativização da coisa julgada.

\section{TITULARIDADE DISJUNTIVA}

A titularidade disjuntiva reflete um aperfeiçoamento do acesso à justiça, em relação à tutela de um bem de uso comum do povo. O macrobem ambiental como bem de uso comum do povo, deve ter seu acesso facilitado pelo direito processual, mitigandose as burocracias do direito de ação. $O$ direito de ação no microssistema do direito ambiental é ampliado também para facilitar a

\footnotetext{
${ }^{5}$ RODRIgueS, M. A. Processo Civil Ambiental. 2. ed. São Paulo: Revista dos Tribunais, 2010. p.73.
} 
fiscalização da exploração dos recursos naturais, ou qualquer conduta capaz de causar poluição ambiental.

Nenhuma lei pode excluir da apreciação do Poder Judiciário lesão ou ameaça a direito $^{6} \mathrm{e}$, por se tratar a tutela ambiental de um interesse público, é dever da sociedade e do poder público tomar as medidas necessárias para a defesa do meio ambiente ecologicamente equilibrado. Há, neste sentido, expressa disposição constitucional ${ }^{7}$ e 0 princípio da indisponibilidade do interesse público aos órgãos públicos.

A titularidade da ação no processo civil ambiental não pode se limitar a legitimidade ordinária do sistema processual comum (art. 6ำ, do Código de Processo Civil). Como visto, nos direitos difusos é impossível se quantificar a titularidade do direito de cada indivíduo, portanto, a titularidade do direito de ação igualmente deve ser difusa, chamada pela doutrina de legitimidade concorrente e disjuntiva.

Fala-se "disjuntiva, porque qualquer um dos legitimados pode atuar em juízo sem necessariamente contar com a participação de outro habilitado" ${ }^{8}$. Ressalta-se, todavia, que a possibilidade de qualquer legitimado atuar em juízo isoladamente, não significa a

\footnotetext{
${ }^{6}$ BRASIL. Constituição (1988). Constituição da República Federativa do Brasil. Art. 5o, inciso XXXV.

${ }^{7}$ BRASIL. Constituição (1988). Constituição da República Federativa do Brasil. Art. 225, caput.

${ }^{8}$ LEONEL, R.B. Manual do processo coletivo. São Paulo: Revista dos Tribunais, 2002. p.162.
}

impossibilidade de litisconsórcio, que é perfeitamente cabível, contudo, não imprescindível.

A legitimidade ativa no processo civil ambiental é também concorrente, pois, qualquer dos legitimados tem a faculdade de propor a ação.

O ordenamento jurídico pátrio elenca como legitimado ativo no processo civil ambiental alguns entes, estatais ou não, elencados no artigo 5ㅇ, da lei $7.347 / 85$, e no artigo 5ํ, LXX, da Constituição Federal. São legitimados também os particulares, que podem exercer individualmente seu direito de ação por meio da Ação Popular, ou ordinária de preceito cominatório. Não obstante a Ação Civil Pública e a Ação Popular sejam os instrumentos judiciais mais utilizados para a tutela do meio ambiente ecologicamente equilibrado, o direito de ação ambiental também pode ser manejado por Mandado de Segurança coletivo, habeas data, mandado de injunção e por ação ordinária de obrigação de fazer ou não fazer, assegurada sempre a possibilidade de ação cautelar ${ }^{9}$ para prevenção do dano.

\section{COMPETÊNCIA DE FORO}

A competência para a interposição da ação é determinada pela localização do dano ambiental, seguindo o disposto no artigo 20 , da lei no $7.347 / 85$.

\footnotetext{
${ }^{9}$ BRASIL. Lei 7.347, de 24 de julho de 1.985. arts. $4 \div$ e 12
} 
A peculiaridade do microssistema ambiental em relação a competência de foto reside no fato de que, por tratar de um macrobem de interesse público, a competência territorial será absoluta, haja vista a maior facilidade de produção das provas. O local do dano é mais propício à melhor instrução processual.

Ainda que se trate de competência da justiça federal ${ }^{10}$, não havendo vara desta justiça especial no local do dano, a competência para a propositura da ação prossegue pelo critério da territorialidade e a demanda seguirá na justiça comum estadual, conforme firmou entendimento o enunciado no 183, da súmula do Superior Tribunal de Justiça $^{11}$.

\section{ÔNUS DA PROVA}

A prova merece especial atenção no processo civil ambiental. O modelo de Estado social tem como pressuposto a intervenção estatal para promoção do bem estar social.O processo, como instrumento de apaziguar conflitos de interesses deve buscar ao máximo a investigação da verdade. A prova é o melhor meio de se chegar à verdade e proferir uma decisão justa, logo, a instrução processual de um processo coletivo não se restringe às partes litigantes, mas é facultado

\footnotetext{
10 BRASIL. Constituição (1988). Constituição da República Federativa do Brasil. art 109.

${ }^{11}$ BRASIL. Superior Tribunal de Justiça. Enunciado 183 da Súmula do STJ: Compete ao juiz estadual, nas comarcas que não sejam sede de vara da Justiça Federal, processar e julgar ação civil pública, ainda que a União figure no processo.
}

ao magistrado determinar a produção das provas que achar necessárias ou convenientes, bem como inverter o ônus da prova, na busca de um resultado justo.

Supera-se aquela imagem do juiz como um mero espectador da instrução processual, típica do pensamento liberal, e se consagra a busca por um julgamento justo, o mais próximo possível da realidade. Isto para que a decisão, de fato, cause um estado de bem estar social.

O juiz tem um papel ativo no processo, mas, deve ser respeitado o contraditório das partes litigantes e a atuação do magistrado é sempre limitada pelo princípio da legalidade, para assegurar a imparcialidade e a justiça do julgamento.

A regra que melhor se aplica à distribuição do ônus da prova nos processos coletivos é a da Teoria da Carga Dinâmica da Prova, haja vista que "[...] as regras do art. 333 do CPC, relativas a distribuição do 'ônus' da prova, ficam extremamente secas e vazias quando passamos a adotar o caráter publicista da prova, dando relevo máximo ao art. 130 do $\mathrm{CPC}^{\prime 12}$.

A Teoria da Carga Dinâmica da Prova estava prevista no artigo 10 , do Anteprojeto de do Código de Processo Coletivo, que deu origem ao Projeto de Lei n.o 5.139/2009, dispondo em seu parágrafo primeiro que o

\footnotetext{
${ }^{12}$ RODRIGUES, M.A. Processo civil ambiental. 2. ed. São Paulo: Revista dos Tribunais, 2010. p.164.
} 
ônus da prova incumbiria à parte que detivesse melhores conhecimentos técnicos ou informações específicas sobre os fatos, ou a maior facilidade na sua demonstração.

Assim, apesar da possibilidade de inversão do ônus da prova, pela carga dinâmica da prova, é o juiz quem decide a quem incidirá o encargo de provar determinados fatos, a partir da hipossuficiência ou hipersuficiência técnica de uma parte em relação à outra. Em não havendo hipossuficiência ou hipersuficiência técnica entre as partes, a regra do ônus probatório seguirá tal qual disposta no artigo 333, do Código de Processo Civil.

A citada disposição contida no Anteprojeto do Código de Processo Coletivo, contudo, não seguiu no texto final que resultou no Projeto de Lei n.o 5.139/2009. Mas isto não significa que o juiz não possa deliberar quanto à carga dinâmica da prova, uma vez que ante o interesse coletivo e indisponibilidade do interesse público discutido nas lides transindividuais, seu poder instrutório encontra limite somente na legalidade dos meios de prova e respeito ao contraditório das partes. Assim determinam as regras dos artigos 130 , do Código de Processo Civil, que concede liberdade ao juiz na instrução processual e 83 , da lei $8.078 / 1990$, que concede ao magistrado a possibilidade de, dentro da legalidade, tomar toda e qualquer providência para conferir efetividade à tutela dos direitos coletivos. A teoria da carga dinâmica da prova ganha espaço na análise dos princípios que norteiam a sistematização do Direito Ambiental.

A regra da teoria da carga dinâmica da prova é muito semelhante à interpretação jurisprudencial sobre inversão do ônus da prova, segundo a qual "[...] não é automática a inversão do ônus da prova. Ela depende de circunstâncias concretas que serão apuradas pelo juiz no contexto da 'facilitação da defesa' dos direitos $[. . .]^{\prime 13}$, ou seja, a regra segue como disposto no artigo 333 , do Código de Processo Civil - quem alega o fato tem o ônus de prova-lo -, contudo, caso haja uma disparidade nas condições de produzi-la, o juiz pode invertê-la, desde que pautado na verossimilhança das alegações da parte beneficiada.

A prova, ou ausência dela, interfere diretamente nos efeitos da coisa julgada do processo. Isto porque se o processo coletivo for julgado improcedente, mas sob o fundamento da insuficiência de provas, os artigos 103 , da lei $8.078 / 90$ e, 16 , da lei $7.347 / 85$, dispõem sobre a possibilidade de qualquer legitimado intentar nova ação com idêntico fundamento, valendo-se de nova prova. Os efeitos da coisa julgada também são peculiares no processo coletivo.

\footnotetext{
13 BRASIL. Superior Tribunal de Justiça. Recurso Especial n. 122.505/SP, Relator Ministro Carlos Alberto Menezes de Direito, Terceira turma. RSTJ, v.115, p. 271.
} 
POSSIBILIDADE

DE

SENTENÇA

CONDENATÓRIA GENÉRICA E REPARAÇÃO

FLUÍDA AOS DANOS INDIVIDUAIS REFLEXOS

Pela indeterminação do sujeito titular do bem ambiental, em regra não cabe delimitação à dimensão subjetiva da tutela, entretanto, é possível que do dano ambiental surjam vítimas diretas, resultando em direito individual homogêneo à indenização. Tomese como exemplos: uma queimada ilícita em imóvel rural, na qual o fogo se espalhe e atinja imóveis vizinhos; o desmatamento indevido de morro que gera deslize de terras que atingem imóveis de terceiros; derramamento de óleo no oceano que prejudique comunidade(s) de pescadores; ou, ainda, aplicação de defensivos agrícolas ou poluição decorrente de produção industrial que causa dano à saúde ou integridade física de pessoas determinadas, como aconteceu com os fetos anencefálicos de Cubatão ${ }^{14}$ e no caso da contaminação radiológica de pessoas por contato Césio $137^{15}$, em Goiânia, na década de oitenta, do século passado.

Nos casos em que, além do dano difuso é possível se identificar danos individuais reflexos, em prejuízo de indivíduos ou grupo de pessoas,o artigo 95

\footnotetext{
${ }^{14}$ ACAYABA, C.; REIS, T. 30 anos após boom de anencéfalos, Cubatão (SP) registra poucos casos. Disponível em: <http://www1.folha.uol.com.br/cotidiano/2008/09/440328-30anos-apos-boom-de-anencefalos-cubatao-sp-registra-poucoscasos.shtml>. Acesso em: 16 ago. 2014.

${ }^{15}$ GOIÁS. Secretaria de Estado de Gestão e Planejamento. Césio 137, - pesadelo que chocou o Brasil. Disponível em: <http://www.cesio137goiania.go.gov.br/index.php?idEditoria=9782 >. Acesso em: 16 ago. 2014.
}

do Código de Defesa do Consumidor (lei 8.072, de 11 de setembro 1990) traz exceção à regra proibitiva de sentença genérica, prevista no artigo 460, parágrafo único, do Código de Processo Civil (lei 5.869, de 11 de janeiro de 1973), que dispõe sobre o dever de a sentença ser sempre certa, ainda que julgue relação jurídica condicional.

Seguindo a possibilidade de sentença genérica, nas lides trasindividuais, o microssistema de processo civil coletivo traz instrumentos de efetividade da tutela jurisdicional. "A sentença será genérica, fixando a responsabilidade do réu pelos danos causados" ${ }^{16}$, porque aproveita um grupo de pessoas atingidas pelo mesmo dano. Assim, é perfeitamente possível, mas, desnecessária a utilização da legitimidade concorrente, uma vez que "[...] os particulares poderão se aproveitar do resultado da ação coletiva (difusa ou individual homogênea) para liquidar os danos individualmente sofridos" ${ }^{17}$. Trata-se da reparação fluída - fluidrecovery -, inspirada na classactions 18, do direito comparado norte americano, cuja aplicação prática vem disciplinada no artigo 100, do Código de Defesa do Consumidor: "Decorrido o prazo de 1 (um) ano sem habilitação de

\footnotetext{
${ }^{16}$ BRASIL. Lei 8.078, de 11 de setembro de 1990, art 95.

${ }^{17}$ RODRIGUES, M.A. Processo civil ambiental. 2. ed. São Paulo: Revista dos Tribunais, 2010. p.227.

${ }^{18}$ ESTADOS UNIDOS DA AMÉRICA. Federal Rules of Civil Procedure, Rule $23, \quad b(3) " . \quad$ Disponível em: <http://www.law.cornell.edu/rules/frcp/rule_23>. Acesso em: 16 ago. 2014
} 
interessados em número compatível com a gravidade do dano, poderão os legitimados do Art. 82 promover a liquidação e execução da indenização devida"19.

O microssistema do processo civil coletivo tem a peculiaridade da sentença condenatória genérica justamente para possibilitar a reparação fluída dos danos individuais reflexos. Os titulares destes danos não precisam ajuizar ações individuais, podendo se aproveitar da sentença condenatória proferida na ação coletiva, que Ihes valerá de título executivo, cabendo-lhes, todavia, na fase da liquidação da sentença, demonstrar a sua titularidade e apurar a extensão da sua reparação.

\section{COISA JULGADA}

Conforme narrado, o macrobem ambiental é o equilíbrio ecológico dos microbens bióticos e abióticos, ou seja, a interação da fauna, da flora e microorganismos como a terra, a água, o ar e o clima, que o tornam um bem indivisível. Além de indivisível, o marcobem ambiental não conhece delimitações espaciais. Não pode uma lei estabelecer fronteiras ao movimento dos ventos, ao regime das chuvas ou aos peixes de um rio. Não há como proteger os peixes do rio Paraná no Estado de São Paulo e deixar de fazê-lo no Estado do Mato Grosso do Sul. Não há como tutelar o ar do Estado do Paraná e deixar de fazê-lo em Santa Catarina. A poluição de um país pode causar impacto negativo em todo o planeta.

A indivisibilidade apontada reflete também na titularidade do macrobem ambiental, que é igualmente difusa. Falar em um macrobem de titularidade difusa é dizer que se trata a tutela ambiental de um bem essencial à sadia qualidade de vida e de titularidade comum do povo, ou seja, é um bem que caso não seja protegido afeta a todos, por isso a coisa julgada no processo ambiental é peculiar e de interesse coletivo.

As principais peculiaridades da coisa julgada no processo ambiental se referem à sua eficácia e aos seus limites subjetivos e objetivos.

Quanto à eficácia, a característica essencial da coisa julgada no processo comum é sua imutabilidade. Ocorre que a eficácia da sentença está ligada à satisfação do direito material do autor. "Toda sentença, porque deve corresponder à pretensão de direito material exposta pelo autor, deve conter, em si, eficácias capazes de corresponder àquela pretensão e, assim, exercer a ação de direito material buscada" ${ }^{20}$, logo, a eficácia preclusiva da coisa julgada no processo civil ambiental apresenta duas considerações a se ponderar: a instabilidade natural dos bens ambientais; e o

\footnotetext{
20 MARINONI, L.G.; ARENHAT S.C. Manual do processo de conhecimento. 3. ed. São Paulo: Revista dos Tribunais, 2004. p.676. 
desconhecimento científico dos impactos ambientais de determinadas ações.

Sabe-se que a natureza é dinâmica, não estática. Os microbens bióticos e abióticos, como os animais, as águas, o movimento das terras e o clima estão em constante mutação há milhares de anos, assim, o que hoje pode não representar dano a determinado ecossistema, amanhã pode Ihe ser extremamente pernicioso.

O que se busca não é a estagnação da natureza, mas sim assegurar sua evolução natural, sem que as intervenções antrópicas levem ao seu esgotamento. Se determinada atividade, inicialmente de baixo impacto ambiental, em razão da mudança climática, do leito do rio, ou qualquer mudança natural, passar a ser de relevante impacto ambiental, a coisa julgada será relativizada e admitir-seá o ajuizamento de nova ação para cessá-la, ou adequá-la à nova situação.

O desconhecimento científico dos impactos ambientais de determinadas atividades também é fator legitimador da relativização da coisa julgada nas lides ambientais. O DDT, por exemplo, era um inseticida inicialmente milagroso contra a malária, largamente utilizado como defensivo agrícola e remédio contra piolhos, que inclusive rendeu um Prêmio Nobel ao seu inventor, mas que, com o passar do tempo, apresentou deformidade nos animais e um elevado potencial nocivo à saúde e à vida animal, vegetal e de seres humanos. Assim, óbvio que a descoberta posterior desse impacto ambiental relevante é motivo suficiente para se relativizar a coisa julgada no processo ambiental.

Rodrigues ressalta que se o objeto da causa se modificar, seja pela instabilidade conatural dos bens ambientais, seja pela descoberta científica de sua potencialidade lesiva ou não, em sendo no curso da demanda, aplica-se o artigo 462, do Código de Processo Civil, que dispõe ao juiz considerar os fatos novos havidos no curso do processo quando da prolação da sentença, mas, se posterior ao trânsito em julgado, não há outra solução senão a relativização da coisa julgada ${ }^{21}$.

Leonel lembra que críticas não faltam acerca da relativização da eficácia preclusiva da coisa julgada no processo coletivo, em especial pelo entendimento de inconstitucionalidade por ofensa ao princípio da igualdade e do devido processo legal, gerando insegurança jurídica ao réu, haja vista que ainda que ganhe a ação, idêntica demanda poder-Ihe-á ser proposta novamente ${ }^{22}$.

A suposta ofensa ao Princípio da igualdade é facilmente rechaçada. Basta lembrar que a igualdade constitucionalmente assegurada é a igualdade substancial, que

\footnotetext{
${ }^{21}$ RODRIGUES, M.A. Processo civil ambiental. 2. ed. São Paulo: Revista dos Tribunais, 2010. p.247.

${ }^{22}$ LEONEL. R. B. Manual do Processo Coletivo, São Paulo: Revista dos Tribunais, 2002. p.262.
} 
consiste em tratar igualmente os iguais e desigualmente os desiguais. Logo, inconstitucional seria conferir igual tratamento entre lides coletivas e individuais, haja vista a larga diferença entre elas, isto seria tratar igualmente os desiguais.

Não há também que se falar em ofensa ao princípio do devido processo legal, ou insegurança jurídica, haja vista ser condição para a propositura de uma nova ação a existência de nova prova, que não existia, ou não poderia ser utilizada no curso do processo. Rodrigues lembra que a regra do deduzido e do dedutível, do artigo 474 do Código de Processo Civil, não se aplica diante de fundamentos inexistentes, ou que não poderiam ser deduzidos, em razão do seu desconhecimento científico no momento do processo, logo, permite-se a nova ação, desde que fundamentada em nova prova ${ }^{23}$.

Quanto a extensão do julgado, embora o artigo 16, da lei 7.374/85 limite os efeitos da sentença ao território do seu órgão prolator, os limites subjetivos e objetivos do processo ambiental, por obviedade, devem ser erga omnes, atingindo toda a territorialidade e todas as pessoas envolvidas, direta ou indiretamente nos fatos apurados na ação. Se o direito é difuso, não há como limitar seus efeitos. Assim, "é ridícula e inócua a limitação territorial

${ }^{23}$ RODRIGUES, M.A. Processo civil ambiental. 2. ed. São Paulo: Revista dos Tribunais, 2010. p.248/249. pretendida pelo legislador. Nem o objeto nem os sujeitos titulares deixarão de ser atingidos, ainda que estejam fora dos lindes da competência territorial do órgão prolator $^{\prime 24}$. Se o objeto da causa é indivisível e sua titularidade é difusa, jamais será possível fracionar os efeitos do julgado sobre os mesmos.

A coisa julgada da tutela ambiental gera, outrossim, a chamada coisa julgada in utilibus, que é a possibilidade de qualquer indivíduo ou grupo ajuizar uma ação, fundada no trânsito em julgado da procedência dos pedidos de uma ação coletiva, iniciando-se a nova demanda diretamente na fase de liquidação de sentença (art. 103, § 3o, da lei $8.078 / 90$ c/c art. 21, da Lei 7.347/85).

\section{CONCLUSÃO}

O microssistema processual estudado traz peculiaridades cuja análise e discussão são imprescindíveis à tutela de direitos difusos. Em síntese podemos apontá-las e descrevê-las da seguinte forma: I. A titularidade disjuntiva é apresentada em prol do alargamento do direito de ação, que tal como o direito material deve ser difuso, haja vista a impossibilidade de quantificação individual da titularidade ao médio ambiente, possibilitando a qualquer legitimado a atuação em juízo; II. O foro competente é

\footnotetext{
${ }^{24}$ RODRIGUES, M.A. Processo civil ambiental. 2. ed. São Paulo: Revista dos Tribunais, 2010. p.249.
} 
determinado pela localização do dano, haja vista as melhores condições de produção da prova e contato com o fato gerador da demanda; III. O ônus da prova será decidido por meio da carga dinâmica da prova, de acordo com a hipo ou hipersufiência das partes na produção da prova, em prol do interesse de que o juiz decida a lide de forma segura, haja vista a indisponibilidade do macrobem ambiental; IV. Admite-se sentença condenatória genérica sobre um bem difuso, para vítimas individuais de danos reflexos possam se aproveitar do resultado da ação coletiva e promover sua liquidação e execução da condenação, tendo em vista seu dano individual; V. Por fim, admite-se a relativização da coisa julgada nas ações coletivas ambientais, haja vista a instabilidade natural dos bens ambientais e desconhecimentos dos impactos externalidades negativas - de determinadas ações, de modo a garantir a proteção do meio ambiente.

Apontadas e discutidas as peculiaridades do microssistema processual coletivo, concernentes ao direito ambiental, conclui-se que o referido microssistema processual visa simplificar e garantir o direito de ação e adaptar normas processuais com foco no acesso à justiça e efetividade do provimento jurisdicional. Isto para garantir a proteção da qualidade da vida humana, mediante a tutela do meio ambiente ecologicamente equilibrado, uma vez que o sistema previsto no Código de Processo Civil é incapaz, por si só, de conferir instrumentos suficientes para satisfazer e efetivar as regulamentações ambientais, contidas nas normas de direito material.

\section{REFERÊNCIAS}

ACAYABA, C.; REIS, T. 30 anos após boom de anencéfalos, Cubatão (SP) registra poucos casos. Disponível em: <http://www1.folha.uol.com.br/cotidiano/20 08/09/440328-30-anos-apos-boom-deanencefalos-cubatao-sp-registra-poucoscasos.shtml>. Acesso em: 16 ago. 2014.

BARBI, C. A. Comentários ao Código de Processo Civil. 10. Ed. Rio de Janeiro: Forense, 1998. v.1.

BRASIL. Lei 5.869, de 11 de janeiro de 1973.

BRASIL. Lei 7.347, de 24 de julho de 1.985 .

BRASIL. Lei 8.078, de 11 de setembro de 1990.

BRASIL. Constituição (1988). Constituição da República Federativa do Brasil. Brasília: Senado Federal, 1988.

BRASIL. Superior Tribunal de Justiça. Enunciado 183 da Súmula do STJ: Compete ao juiz estadual, nas comarcas que não sejam sede de vara da Justiça Federal, processar e julgar ação civil pública, ainda que a União figure no processo.

BRASIL, Superior Tribunal de Justiça, Recurso Especial n. 122.505/SP, Relator Ministro Carlos Alberto Menezes de Direito, Terceira turma, RSTJ. vol. 115, p. 271.

ESTADOS UNIDOS DA AMÉRICA. Federal Rulesof Civil Procedure, Rule 23, Disponível 
em:

http://www.law.cornell.edu/rules/frcp/rule_ 23. Acesso em 16 ago. 2014.

GOIÁS. Secretaria de Estado de Gestão e Planejamento. Césio 137, o pesadelo que chocou o Brasil. Disponível em: http://www.cesio137goiania.go.gov.br/index .php?idEditoria=9782. Acesso em 16 ago. 2014.

LEONEL. R. de B. Manual do Processo Coletivo, São Paulo: Revista dos Tribunais, 2002.

MANCUSO, Rodolfo de Camargo. Interesses Difusos: Conceito e legitimação para agir, 3a ed. rev. e atual., São Paulo: Revista dos Tribunais, 1994.

MARINONI, Luís Guilherme; ARENHAT S.C. Manual do Processo de Conhecimento, 3a ed., São Paulo: Revista dos Tribunais, 2004.

PORTUGAL. Constituição (VII Revisão Constitucional). disponível em: http://www.parlamento.pt/Legislacao/Pagin as/ConstituicaoRepublicaPortuguesa.aspx. Acesso em 18. Julh. 2012.

RODRIGUES, Marcelo Abelha. Processo Civil Ambiental, 2a ed., São Paulo: Revista dos Tribunais, 2010.

SOUZA, Paulo Roberto Pereira. in: Meio Ambiente: Memória e Compromissos da Ordem dos Advogados do Brasil: 1989/2012 / coord. Maria Arres Hermans, Brasília: OAB, Conselho Federal, Comissão Nacional de Direito Ambiental, 2012.

Recebido para publicação em 19/08/2014

Revisado em 01/09/2014

Aceito em 06/09/2014 